\title{
Produção de fitomassa e acúmulo de nutrientes por plantas de cobertura no cerrado piauiense
}

Leandro Pereira Pacheco $\left({ }^{1 *}\right)$; Marinete Martins de Sousa Monteiro $\left({ }^{2}\right)$; Rodrigo Fonseca da Silva $\left({ }^{3}\right)$; Leandro dos Santos Soares (3); Wéverson Lima Fonseca (4); Julio César Azevedo Nóbrega ( ${ }^{3}$ );

Fabiano André Petter ( ${ }^{5}$ ); Francisco de Alcântara Neto $\left({ }^{6}\right)$; Josy Anteveli Osajima $\left({ }^{7}\right)$

(') Universidade Federal de Mato Grosso (UFMT), Engenharia Agrícola e Ambiental, 78735-000 Rondonópolis (MT), Brasil.

(2) Universidade Federal do Piauí (UFPI), Programa de Pós-Graduação em Agronomia - Fitotecnia, 64900-000 Bom Jesus (PI), Brasil.

(3) UFPI, Programa de Pós-Graduação em Solos e Nutrição de Plantas, 64900-000 Bom Jesus (PI), Brasil.

(4) UFPI, Graduação em Agronomia, 64900-000 Bom Jesus (PI), Brasil.

(5) UFMT, Departamento de Fitotecnia, 78557-267 Sinop (MT), Brasil.

${ }^{(6)}$ UFPI, Departamento de Fitotecnia, 64049-000 Teresina (PI), Brasil.

(7) UFPI, Departamento de Química, 64900-000 Bom Jesus (PI), Brasil.

(*) Autor correspondente: leandroppacheco@gmail.com

Recebido: 20/abr./2013; Aceito: 31/ago./2013

\begin{abstract}
Resumo
O objetivo deste trabalho foi avaliar o potencial de plantas de cobertura semeadas em diferentes sistemas de cultivo quanto à produção de fitomassa e acúmulo de nutrientes, no cerrado piauiense. O experimento foi instalado no ano agrícola 2010/2011, na Serra do Quilombo, município de Bom Jesus (Piauí). O arranjo utilizado foi em parcelas subdivididas, com os seguintes sistemas de manejo do solo: preparo convencional e plantio direto avaliados nas parcelas e, nas subparcelas, os sistemas de produção: $S_{1}$ - Soja no verão em monocultura; $S_{2}$ - Soja no verão e Penissetum glaucum na safrinha; $S_{3}$ - P. glaucum pré-soja de verão e sobressemeadura de Urochloa ruziziensis na soja no estádio $R_{5.5} ; S_{4}$ - Soja de verão e sobressemeadura de $P$. glaucum na soja no estádio $\mathrm{R}_{5.5} ; \mathrm{S}_{5}$ - Milho verão + U. ruziziensis simultâneo. Utilizou-se o delineamento em blocos casualizados, com quatro repetições. Os sistemas com a sobressemeadura do P. glaucum e do U. ruziziensis na soja e o consórcio de milho + U. ruziziensis destacaram-se na produção de fitomassa seca, cobertura do solo e acúmulo de nutrientes durante a entressafra no cerrado piauiense. Os nutrientes com maior taxa de acúmulo pelas plantas de cobertura foram o nitrogênio e o potássio.
\end{abstract}

Palavras-chave: Braquiária, milheto, decomposição, crotalária, plantio direto.

\section{Biomass production and nutrient accumulation by cover crops in the Brazilian Cerrado of Piauí State}

\section{Abstract}

The objective of this work was to evaluate the biomass production and nutrient accumulation in potential cover crops sown in different cropping systems in the Brazilian Cerrado of Piauí State. The experiment was conducted in the crop season 2010/2011 in the Serra do Quilombo, county of Bom Jesus, Piauí, Brazil. This study was arranged in split plot scheme, with soil management systems (conventional tillage and no-tillage) evaluated in plots and crop systems in subplots: $\mathrm{S}_{1}$ - Soybean monoculture in the crop-season; $\mathrm{S}_{2}$ - Soybean in crop-season and Pennisetum glaucum for off-season; $\mathrm{S}_{3}$ - P. glaucum before soybean crop-season and Urochloa ruziziensis oversown on soybean in the phenological stage $\mathrm{R}_{5.5} ; \mathrm{S}_{4}$ - Soybean crop-season and $P$. glaucum oversown on soybean in $R_{5,5} ; S_{5}$ - Maize $+U$. ruziziensis simultaneously in crop-season. The experimental design was in randomized blocks, with four replications. The crop systems with oversown of $P$. glaucum and U. ruziziensis on soybean and the consortium maize + U. ruziziensis improved the biomass production, soil coverage and nutrient accumulation during the off-season in the Cerrado from Piauí State, Brazil. The nutrients with greater accumulation rate by cover crops were nitrogen and potassium.

Key words: Brachiaria, millet, decomposition, crotalaria, no-tillage. 


\section{INTRODUÇÃO}

O cerrado piauiense apresenta-se como uma nova fronteira agrícola do país, com condiçôes edafoclimáticas favoráveis ao cultivo de culturas anuais. Na safra 2011/2012, as áreas cultivadas com soja, milho e arroz no Piauí foram de 438,8; 357,3 e 141,9 mil ha, respectivamente, com destaque para o aumento de $17 \%$ na área cultivada com soja em relaçáo à safra anterior (ConAB, 2012). O sistema de preparo convencional do solo (SPC) tem sido prática bastante utilizada por produtores de grãos dessa região (Pragana et al., 2012), o que tem ocasionado a degradaçáo do solo, perdas na produtividade a médio prazo e disseminação de doenças, com destaque para a elevada infestaçáo de nematoides.

O uso de tecnologias como o sistema plantio direto (SPD) (Carvalho et al., 2011), com uso de plantas de cobertura do solo e a prática de rotaçáo de culturas (MORETı et al., 2007), podem representar opção viável para reduzir os impactos no uso intensivo do solo e favorecer as propriedades químicas, físicas e biológicas do solo (CARNeIro et al., 2008; SiLva et al., 2011). Ao considerar que o índice pluviométrico do cerrado piauiense é menor se comparado ao de outras regiōes, a presença de quantidades significativas de biomassa sobre a superfície do solo pode causar maior retenção e eficiência no uso da água pela planta.

O SPD consolidou-se como tecnologia conservacionista entre os agricultores de outras regióes do cerrado (CRUZ e Ciociola Júnior, 2006). A sua eficácia se relaciona, dentre outros fatores, à quantidade e qualidade dos resíduos culturais, sendo esse, talvez, o seu grande trunfo para a sustentabilidade no cerrado (Pires et al., 2008). Dessa forma, as plantas de cobertura precisam apresentar elevada capacidade de produção de fitomassa, seus resíduos devem apresentar persistência sobre a superfície do solo e, sobretudo, capacidade de promover significativa ciclagem de nutrientes (Crusciol et al., 2005).

Nas condiçōes edafoclimáticas de cerrado, as gramíneas têm sido bastante utilizadas como plantas de cobertura, com destaque para o milheto (Pennisetum glaucum) e espécies de Urochloa spp., devido a sua maior resistência ao déficit hídrico e à elevada produção de fitomassa (BorGHI et al., 2006; Lara-Cabezas et al., 2004). De acordo com Crusciol e Soratto (2007), P. glaucum é uma espécie de alta capacidade de extração de nutrientes do solo, principalmente de nitrogênio $(\mathrm{N})$ e potássio $(\mathrm{K})$, reduzindo assim os riscos de perda desses nutrientes por lixiviaçáo. $\mathrm{O}$ uso de plantas de cobertura com hábito perene, como a braquiária (Urochloa ruziziensis), proporciona significativo acúmulo de fitomassa, apresentando reduzida decomposição durante a entressafra (PACHeco et al., 2008). Além do mais, essa espécie apresenta significativa rebrota após o reinício das chuvas, o que pode favorecer a produçáo de fitomassa nos sistemas agrícolas.

As tecnologias mencionadas ainda não estão adaptadas às condições edafoclimáticas do cerrado sul-piauiense e os produtores rurais apresentam resultados insatisfatórios com o uso do SPD, comprometendo assim sua adoção na região. Estudos que possam identificar técnicas de introdução de plantas de cobertura capazes de promover elevada produçáo de fitomassa, acúmulo de nutrientes e taxa de cobertura do solo nas culturas de soja e milho desenvolvidas no Piauí podem favorecer a expansão do SPD. O objetivo deste trabalho foi avaliar o potencial de plantas de cobertura semeadas em diferentes sistemas de cultivo quanto à produção de fitomassa e acúmulo de nutrientes no cerrado piauiense.

\section{MATERIAL E MÉTODOS}

O experimento foi instalado no ano agrícola 2010/2011, no período de dezembro de 2010 a novembro de 2011, na Serra do Quilombo, localizada no município de Bom Jesus

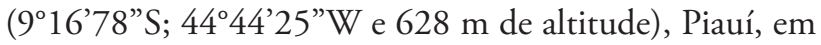
um Latossolo Amarelo distrófico (Pragana et al., 2012) cujas características químicas e texturais são apresentadas na Tabela 1. O solo foi cultivado com soja durante a safra e P. glaucum na safrinha, em sistema de plantio direto, nos quatro anos anteriores. O clima da localidade de estudo, segundo a classificação de Köppen, é do tipo Aw. A precipitação e temperatura médias mensais durante o experimento estâo apresentadas na Figura 1.

$\mathrm{O}$ arranjo experimental utilizado foi em blocos ao acaso, em esquema com parcelas subdivididas, com quatro repetiçôes. As parcelas foram constituídas pelos sistemas de manejo do solo: preparo convencional (SPC) e sistema plantio direto (SPD). As subparcelas foram constituídas pelos sistemas de produção (Tabela 2): $S_{1}$ - Soja no verão em monocultura; $\mathrm{S}_{2}$ - Soja no verão e P. glaucum $\left(20 \mathrm{~kg} \mathrm{ha}^{-1}\right)$ na safrinha; $S_{3}-P$. glaucum pré-soja de verão e sobressemeadura de Urochloa ruziziensis (13 $\mathrm{kg} \mathrm{ha}^{-1}$, Valor Cultural: 60) na soja no estádio $\mathrm{R}_{5.5} ; \mathrm{S}_{4}$ - Soja de verão e sobressemeadura de

Tabela 1. Caracterização química e textural do Latossolo Amarelo sob cultivo com diferentes sistemas de produção, em sistema plantio direto e convencional, durante a pré-safra, safra 2010/2011, no cerrado piauiense

\begin{tabular}{|c|c|c|c|c|c|c|c|c|c|c|c|c|}
\hline \multirow{2}{*}{$\begin{array}{l}\text { Profundidade } \\
\text { (m) }\end{array}$} & \multirow{2}{*}{$\begin{array}{c}\mathrm{pH} \\
\left(\mathrm{CaCl}_{2}\right)\end{array}$} & $\mathbf{P}$ & $\mathbf{K}^{+}$ & $\mathrm{Ca}^{2+}$ & $\mathrm{Mg}^{2+}$ & $\mathrm{H}+\mathrm{Al}$ & $T$ & \multirow{2}{*}{$\begin{array}{c}\text { V } \\
(\%)\end{array}$} & \multirow{2}{*}{$\begin{array}{c}\text { MO } \\
\left(\mathrm{g} \mathrm{dm}^{-3}\right)\end{array}$} & Areia & \multirow{2}{*}{$\begin{array}{c}\text { Silte } \\
\left(\mathrm{g} \mathrm{kg}^{-1}\right)\end{array}$} & \multirow[t]{2}{*}{ Argila } \\
\hline & & \multicolumn{2}{|c|}{$\left(\mathrm{mg} \mathrm{dm}^{-3}\right)$} & \multicolumn{4}{|c|}{$\left(\mathrm{cmol}_{\mathrm{c}} \mathrm{dm}^{-3}\right)$} & & & & & \\
\hline $0,00-0,20$ & 4,9 & 29,6 & 44 & 2,3 & 0,9 & 3,4 & 6,71 & 49 & 14 & 686 & 20 & 294 \\
\hline $0,20-0,40$ & 4,1 & 9,1 & 25 & 1,0 & 0,5 & 3,1 & 4,67 & 34 & 13 & 666 & 40 & 294 \\
\hline
\end{tabular}

$\mathrm{P}$ = fósforo disponível; $\mathrm{K}^{+}, \mathrm{Ca}^{2+}$ e $\mathrm{Mg}^{2+}$ trocáveis; $\mathrm{H}+\mathrm{Al}=$ acidez potencial; $\mathrm{T}$ = capacidade de troca de cátions a $\mathrm{pH}$ 7,0; $\mathrm{V}=$ saturação por bases; e $\mathrm{MO}=$ matéria orgânica 
P. glaucum $\left(25 \mathrm{~kg} \mathrm{ha}^{-1}\right)$ na soja no estádio $\mathrm{R}_{5.5} ; \mathrm{S}_{5}$ - Milho verão $+U$. ruziziensis simultâneo $\left(10 \mathrm{~kg} \mathrm{ha}^{-1}\right.$, VC: 60$)$. As unidades experimentais constaram de $1.500 \mathrm{~m}^{2}(30 \times 50 \mathrm{~m})$ e a área útil considerada foi de $800 \mathrm{~m}^{2}(20 \times 40 \mathrm{~m})$.

Em SPC, os solos foram submetidos a gradagem aradora, seguida de gradegem niveladora, 45 dias antes da semeadura das culturas anuais. No SPD realizou-se a dessecação de manejo para a semeadura das culturas anuais, com uso de glyphosate ( 1.440 g i.a. ha $\left.{ }^{-1}\right) 10$ dias antes da sua semeadura. A semeadura dos tratamentos com soja no verão $\left(S_{1}, S_{2}, S_{3}\right.$ e $S_{4}$ ) foi realizada em 12 de dezembro de 2010, com semeadora pneumática de precisão, utilizando-se o cultivar MSOY $9144 \mathrm{RR}^{\circ}$, com as sementes inoculadas com Bradyrhizobium japonicum, espaçamento entre linhas de $0,50 \mathrm{~m}$ e estande de 12 plantas $\mathrm{m}^{-1}$, densidade populacional de $240 \mathrm{mil}$ plantas ha ${ }^{-1}$, adubadas com $500 \mathrm{~kg} \mathrm{ha}^{-1}$ de fertilizante NPK (00-20-10). Quando a soja atingiu o estádio fenológico $V_{4}$ procedeu-se a uma adubaçáo de cobertura com cloreto de potássio $(\mathrm{KCl})$, com dosagem de $60 \mathrm{~kg} \mathrm{ha}^{-1}$. A semeadura do milho no tratamento $\mathrm{S}_{5}$ foi realizada em 19 de dezembro de 2010, com uso do híbrido PIONEER 30A04, em espaçamento $0,50 \mathrm{~m}$ entre linhas e estande de 2,8 plantas $\mathrm{m}^{-1}$, densidade populacional de 56 mil plantas ha ${ }^{-1}$, adubadas com $500 \mathrm{~kg} \mathrm{ha}^{-1}$ de fertilizante NPK (08-20-20). A adubação de cobertura foi executada a lanço quando o milho apresentava quatro folhas expandidas, com $100 \mathrm{~kg} \mathrm{ha}^{-1} \mathrm{de} \mathrm{N}$ na forma de uréia.

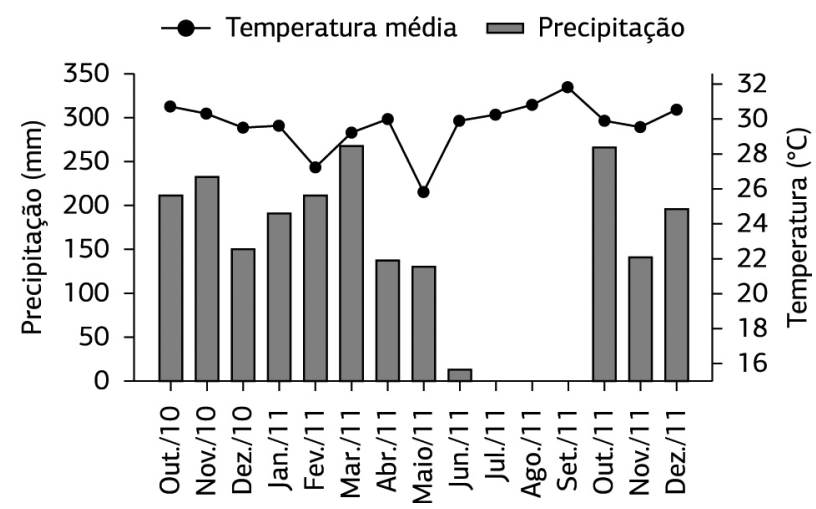

Figura 1. Precipitação mensal e temperatura média do ar durante a condução do experimento, em Bom Jesus, PI.
Nos tratamentos $\mathrm{S}_{3}$ e $\mathrm{S}_{4}$, a sobressemeadura das plantas de cobertura foi realizada a lanço, no momento que a soja estava no estádio $\mathrm{R}_{5.5}$ ( $80 \%$ de enchimento de grãos). Nos tratamentos em que as plantas de cobertura foram semeadas na safrinha $\left(S_{2}\right)$, a semeadura foi realizada imediatamente após a colheita das culturas anuais, que ocorreu em 16 de abril de 2011. Ainda no tratamento $S_{3}$, o P. glaucum foi semeado em pré-semeadura da soja ( 45 dias antes da semeadura da soja). No tratamento $S_{5}$, consórcio de milho + U. ruziziensis, a planta de cobertura foi semeada com as sementes misturadas ao adubo da semeadura do milho.

Em cada unidade experimental foram quantificados a fitomassa seca (FS) e a taxa de cobertura do solo (TCS) promovida pelas plantas de cobertura (retirando-se os restos culturais da soja e do milho). Essas avaliaçôes foram realizadas no momento da dessecação $(23 / 11 / 2010)$ para a semeadura da safra 2010/2011 e aos 20, 50, 80, 120, 160, 200 e 230 dias após a colheita das culturas (dac), conduzidas no período de 16 de abril de 2011 (início da entressafra) até 29 de novembro de 2011 (final da entressafra). Quantificou-se também a FS advinda dos restos culturais da soja $\left(S_{1}, S_{2}, S_{3}\right.$ e $\left.S_{4}\right)$ e do milho $\left(S_{5}\right)$ imediatamente após a colheita de grãos.

As avaliaçóes de FS das plantas de cobertura e dos restos culturais das culturas foram realizadas em todas as subparcelas segundo metodologia proposta por CRUsCiOl et al. (2005), que consiste no uso de uma guia com $0,50 \times 0,50 \mathrm{~m}\left(0,25 \mathrm{~m}^{2}\right)$. A parte aérea e os resíduos das plantas de cobertura foram coletados em quatro pontos de amostragem por subparcela, de forma náo coincidente com os locais de determinaçáo da produtividade de gráos. Em seguida, as amostras foram desidratadas em estufa $\left(60^{\circ} \mathrm{C}\right.$ por 72 horas) e pesadas para obtençáo da FS. Os resíduos das plantas de cobertura foram triturados em moinho tipo Willey (malha de $2 \mathrm{~mm}$ ) para a determinação das concentraçóes de $\mathrm{N}, \mathrm{P}, \mathrm{K}, \mathrm{Ca}$ e $\mathrm{Mg}$, seguindo-se as metodologias propostas por Nogueira et al. (2005). Em seguida, a quantidade de nutrientes acumulados pelas plantas de cobertura foi estimada em $\mathrm{kg} \mathrm{ha}^{-1}$. A TCS foi estimada com uso da guia $\left(0,25 \mathrm{~m}^{2}\right)$ e uma rede de barbantes espaçados a $5 \mathrm{~cm}$, formando dez pontos. Observou-se a presença ou ausência de cobertura proporcionada pelos resíduos vegetais em cada um dos pontos de amostragem de FS (Sodré Filho et al., 2004).

Tabela 2. Caracterização dos tratamentos nas subparcelas com diferentes sistemas de produção, em plantio direto e convencional, durante a pré-safra, safra 2010/2011 e entressafra, no cerrado piauiense

\begin{tabular}{|c|c|c|c|}
\hline \multirow{2}{*}{$\begin{array}{l}\text { Sistema de } \\
\text { produção }\end{array}$} & Pré-safra & Safra 2010/2011 & Entressafra \\
\hline & Outubro de 2010 & Dezembro de 2010 a abril de 2011 & Abril de 2011 a novembro de 2011 \\
\hline $\mathrm{S}_{1}$ & -- & Soja & Pousio \\
\hline $\mathrm{S}_{2}$ & -- & Soja & P. glaucum ADR300 (1) \\
\hline $\mathrm{S}_{3}$ & P. glaucum ADR300 - $20 \mathrm{~kg} \mathrm{ha}^{-1(1)}$ & $\begin{array}{c}\text { Soja + sobressemeadura U. ruziziensis - } \\
13 \mathrm{~kg} \mathrm{ha}^{-1} \text {, Valor Cultural: } 60^{(2)}\end{array}$ & U. ruziziensis \\
\hline $\mathrm{S}_{4}$ & -- & $\begin{array}{l}\text { Soja + sobressemeadura } P \text {. glaucum } \\
\text { ADR300 - } 25 \mathrm{~kg} \mathrm{ha}^{-1}\end{array}$ & P. glaucum ADR300 \\
\hline $\mathrm{S}_{5}$ & -- & Milho + U. ruziziensis & U. ruziziensis \\
\hline
\end{tabular}

${ }^{(1)}$ Semeadura realizada à lanço; ${ }^{(2)}$ sobressemeadura no momento em que a soja apresentava, aproximadamente, $80 \%$ de enchimento de grãos $\left(\mathrm{R}_{5.5}\right)$ 
Foram utilizadas duas equações de regressão que explicaram o acúmulo de fitomassa e nutrientes, sendo os sistemas $S_{1}$ e $\mathrm{S}_{2}$ ajustados à equação polinomial linear $\mathrm{Y}=\mathrm{y}_{0}+a^{*} x$, em que $Y$ é a quantidade acumulada de fitomassa ou nutriente; $\mathrm{y}_{0}$ é a quantidade inicial de fitomassa; $a$ é um coeficiente de ajuste de erro e $x$ é a data na qual foi realizada a coleta. Para $\mathrm{S}_{3}, \mathrm{~S}_{4}$ e $\mathrm{S}_{5}$ utilizou-se a equação exponencial crescente $\mathrm{Y}=\mathrm{y}_{0}+a^{*} \exp \left(b^{*} x\right)$, onde $\mathrm{Y}$ é a quantidade acumulada de fitomassa ou nutriente; $a$ e $b$ sáo coeficientes de ajuste de erro da equação e $x$ é a data na qual foi realizada a coleta.

Os resultados foram submetidos à análise de variância e as médias, comparadas pelo teste de Tukey $(\mathrm{p}<0,05)$. Os ajustes das equaçóes foram realizados com o programa Sigma Plot 10.1 (San José, CA, EUA).

\section{RESULTADOS E DISCUSSÃO}

Houve interação significativa entre os sistemas de manejo do solo e os sistemas de produção quanto à produção de FS, TCS e quantidade de nutrientes acumulados (N, P, K,
$\mathrm{Ca}$ e $\mathrm{Mg}$ ) na maioria das épocas avaliadas (Tabela 3). No momento da dessecaçáo de manejo para semeadura das culturas anuais, a ausência de revolvimento do solo no SPD possibilitou maior presença de FS na superfície do solo, TCS e acúmulo de nutrientes (Tabelas 4 a 6). É importante destacar que o $P$. glaucum semeado em pré-semeadura da soja no $S_{3}$ não causou incremento nas variáveis analisadas, uma vez que a área em estudo apresentava presença de sementes, oriundas da entressafra anterior, suficientes para proporcionar a germinação e desenvolvimento dessa espécie em todos os tratamentos. Pacheco et al. (2011) também relataram a possibilidade de sementes de $P$. glaucum oriundas da entressafra promoverem significativa emergência de novas plantas após o reinício das chuvas e acúmulo de fitomassa.

Os sistemas com uso de sobressemeadura de $U$. ruziziensis $\left(\mathrm{S}_{3}\right)$ e $P$. glaucum $\left(\mathrm{S}_{4}\right)$ na soja e o consórcio simultâneo de milho $+U$. ruziziensis $\left(\mathrm{S}_{5}\right)$ destacaram-se como opçóes mais promissoras para produção de FS e TCS durante a entressafra (Tabela 4). Observou-se que o P. glaucum e a $U$. ruziziensis apresentaram elevados índices de germinação e adequado estabelecimento após a sobressemeadura na soja,

Tabela 3. Análise de variância (valores de F) para fitomassa seca, taxa de cobertura e nutrientes, em função de plantas de cobertura durante a entressafra no cerrado piauiense

\begin{tabular}{|c|c|c|c|c|c|c|c|c|}
\hline \multirow{2}{*}{$\begin{array}{l}\text { Variável/Fontes } \\
\text { de variação }\end{array}$} & \multirow[t]{2}{*}{ Dessecação(1) } & \multicolumn{7}{|c|}{ Dias após a colheita (dac) - Entressafra } \\
\hline & & 20 & 50 & 80 & 120 & 160 & 200 & 230 \\
\hline \multicolumn{9}{|l|}{ Fitomassa seca } \\
\hline Manejo & $894,79^{* *}$ & $1,23 \mathrm{~ns}$ & $5,55^{*}$ & $7,35^{*}$ & $22,89^{*}$ & $15,39^{*}$ & $2.646,34^{* *}$ & $1.282,30^{* *}$ \\
\hline Sistema & $4,34^{* *}$ & $15,72^{* *}$ & $5,65^{* *}$ & $12,65^{* *}$ & $20,32^{* *}$ & $34,53^{* *}$ & $21,66^{* *}$ & $45,98^{* *}$ \\
\hline Manejo x Sistema & $4,34^{* *}$ & $3,51^{*}$ & $5,87^{* *}$ & $1,40 \mathrm{~ns}$ & $2,95^{*}$ & $1,69 \mathrm{~ns}$ & $21,66^{* *}$ & $45,98^{* *}$ \\
\hline \multicolumn{9}{|l|}{ Taxa de cobertura } \\
\hline Manejo & $3.212,53^{* *}$ & $0,20 \mathrm{~ns}$ & $0,98 \mathrm{~ns}$ & $4,52^{*}$ & $1,78 \mathrm{~ns}$ & $5,37^{*}$ & $7.990,81^{* *}$ & $36.736,12^{* *}$ \\
\hline Sistema & $3,50^{* *}$ & $14,66^{* *}$ & $30,00^{* *}$ & $32,10^{* *}$ & $37,07^{* *}$ & $123,65^{* *}$ & $7,92^{* *}$ & $26,11^{* *}$ \\
\hline Manejo x Sistema & $3,50^{* *}$ & $2,64^{*}$ & $1,84 \mathrm{~ns}$ & $1,56 \mathrm{~ns}$ & $1,08 \mathrm{~ns}$ & $2,83^{*}$ & $7,92^{* *}$ & $26,11^{\text {** }}$ \\
\hline \multicolumn{9}{|l|}{ Nitrogênio } \\
\hline Manejo & $1.177,26^{* *}$ & $0,99 \mathrm{~ns}$ & $1,93 \mathrm{~ns}$ & $0,43 n s$ & $3,79 \mathrm{~ns}$ & $3,22 \mathrm{~ns}$ & $3.738,27^{* *}$ & $9.584,84^{* *}$ \\
\hline Sistema & $11,09^{* *}$ & $68,40^{* *}$ & $79,96^{* *}$ & $144,99^{* *}$ & $160,07^{* *}$ & $194,60^{* *}$ & $111,17^{* *}$ & $563,84^{* *}$ \\
\hline Manejo x Sistema & $11,09^{* *}$ & $0,80 \mathrm{~ns}$ & $1,87 \mathrm{~ns}$ & $1,38 \mathrm{~ns}$ & $0,88 \mathrm{~ns}$ & $0,63 n s$ & $111,17^{* *}$ & $563,84^{* *}$ \\
\hline \multicolumn{9}{|l|}{ Fósforo } \\
\hline Manejo & $5.785,62^{* *}$ & $28,18^{*}$ & $38,57^{* *}$ & $44,95^{* *}$ & $39,36^{* *}$ & $37,00^{* *}$ & $5.013,77^{* *}$ & $4.672,83^{* *}$ \\
\hline Sistema & $7,31^{* *}$ & $21,89^{* *}$ & $19,02^{* *}$ & $31,65^{* *}$ & $10,35^{* *}$ & $20,39 * *$ & $31,77^{* *}$ & $194,99 * *$ \\
\hline Manejo x Sistema & $7,31^{* *}$ & $18,96^{* *}$ & $10,61^{* *}$ & $11,61^{* *}$ & $9,78^{* *}$ & $10,89^{* *}$ & $31,77^{* *}$ & $194,99^{* *}$ \\
\hline \multicolumn{9}{|l|}{ Potássio } \\
\hline Manejo & $1.241,29^{* *}$ & $47,00^{* *}$ & $35,41^{* *}$ & $29,86^{*}$ & $1,76 \mathrm{~ns}$ & $1,39 \mathrm{~ns}$ & $4.861,92^{* *}$ & $17.325,77^{* *}$ \\
\hline Sistema & $81,44^{* *}$ & $131,77^{* *}$ & $168,19^{* *}$ & $185,07^{* *}$ & $279,84^{* *}$ & $113,17^{* *}$ & $153,87^{* *}$ & $1.446,62^{* *}$ \\
\hline Manejo x Sistema & $81,44^{* *}$ & $18,63^{* *}$ & $1,99 \mathrm{~ns}$ & $8,40^{* *}$ & $13,71^{* *}$ & $18,19^{* *}$ & $153,87^{* *}$ & $1.446,62^{* *}$ \\
\hline \multicolumn{9}{|l|}{ Cálcio } \\
\hline Manejo & $4.161,25^{* *}$ & $165,21^{* *}$ & $45,37^{* *}$ & $14,65^{*}$ & $0,26 \mathrm{~ns}$ & $0,09 \mathrm{~ns}$ & $5.370,22^{* *}$ & $8.942,04^{* *}$ \\
\hline Sistema & $27,82^{* *}$ & $210,76^{* *}$ & $83,11^{* *}$ & $99,37^{* *}$ & $18,61^{* *}$ & $14,51^{* *}$ & $6,49^{* *}$ & $115,59^{* *}$ \\
\hline Manejo x Sistema & $27,82^{* *}$ & $56,97^{* *}$ & $16,61^{* *}$ & $6,38^{* *}$ & $0,93 n s$ & $0,13 n s$ & $6,49^{* *}$ & $115,59^{* *}$ \\
\hline \multicolumn{9}{|l|}{ Magnésio } \\
\hline Manejo & $1.894,62^{* *}$ & $2,58 \mathrm{~ns}$ & $0,004 \mathrm{~ns}$ & $4,53 n s$ & $29,87^{* *}$ & $66,16^{* *}$ & $6.402,89^{* *}$ & $4.265,88^{* *}$ \\
\hline Sistema & $3,63^{*}$ & $16,56^{* *}$ & $12,43^{* *}$ & $41,70^{* *}$ & $32,25^{* *}$ & $27,93^{* *}$ & $21,63^{* *}$ & $93,20^{* *}$ \\
\hline Manejo x Sistema & $3,63^{*}$ & $12,69^{* *}$ & $4,25^{* *}$ & $5,89^{* *}$ & $3,97^{*}$ & $0,81 \mathrm{~ns}$ & $21,63^{* *}$ & $93,20^{* *}$ \\
\hline
\end{tabular}

${ }^{1}$ Dessecação de manejo realizada em 23 de novembro de 2010; ns: F não significativo; *: F significativo a 5\%; **: F significativo a 1\% 
Tabela 4. Fitomassa seca e taxa de cobertura do solo observada durante o período de entressafra em diferentes sistemas de manejo com culturas anuais e plantas de cobertura no fim da safra 2010/2011 até a safra 2011/2012, avaliadas em sete épocas no cerrado piauiense

\begin{tabular}{|c|c|c|c|c|c|c|}
\hline \multirow[t]{4}{*}{ Sistema ${ }^{(2)}$} & \multicolumn{2}{|c|}{ Dessecação* } & \multicolumn{4}{|c|}{$\operatorname{dac}^{(1)}$} \\
\hline & & & \multicolumn{2}{|c|}{160} & \multicolumn{2}{|c|}{230} \\
\hline & SPC & SPD & SPC & SPD & SPC & SPD \\
\hline & \multicolumn{6}{|c|}{ Fitomassa seca $\left(\mathrm{kg} \mathrm{ha}^{-1}\right)$} \\
\hline $\mathrm{S}_{1}^{* *}$ & $0,0 \mathrm{Ba}$ & $1.527,8 \mathrm{Abc}$ & $4.383,3 \mathrm{Ab}$ & $3.944,4 \mathrm{Bb}$ & $0,0 \mathrm{Ba}$ & $4.779,3 \mathrm{Ac}$ \\
\hline $\mathrm{S}_{2}$ & $0,0 \mathrm{Ba}$ & $1.900,0 \mathrm{Aa}$ & $4.338,9 \mathrm{Ab}$ & $4.305,5 \mathrm{Ab}$ & $0,0 \mathrm{Ba}$ & $4.908,2 \mathrm{Ac}$ \\
\hline $\mathrm{S}_{3}$ & $0,0 \mathrm{Ba}$ & 1.616,7 Aab & $6.327,8 \mathrm{Aa}$ & $5.583,3 \mathrm{Ba}$ & $0,0 \mathrm{Ba}$ & $10.842,1 \mathrm{Ab}$ \\
\hline $\mathrm{S}_{4}$ & $0,0 \mathrm{Ba}$ & 1.644,4 Aab & $6.488,9 \mathrm{Aa}$ & $5.911,1 \mathrm{Aa}$ & $0,0 \mathrm{Ba}$ & $12.743,2 \mathrm{Aa}$ \\
\hline $\mathrm{S}_{5}$ & $0,0 \mathrm{Ba}$ & $1.216,7 \mathrm{Ac}$ & $6.827,8 \mathrm{Aa}$ & $5.544,4 \mathrm{Ba}$ & $0,0 \mathrm{Ba}$ & 11.193,0 Aab \\
\hline $\mathrm{CV}(\%)$ & \multicolumn{2}{|c|}{21,1} & \multicolumn{2}{|c|}{9,3} & \multicolumn{2}{|c|}{17,7} \\
\hline DMS & \multicolumn{2}{|c|}{342,9} & \multicolumn{2}{|c|}{$1.018,0$} & \multicolumn{2}{|c|}{$1.611,3$} \\
\hline \multicolumn{7}{|c|}{ Taxa de cobertura do solo (\%) } \\
\hline $\mathrm{S}_{1}^{* *}$ & $0,0 \mathrm{Ba}$ & 66,7 Aab & $83,6 \mathrm{Ac}$ & $85,8 \mathrm{Ab}$ & $0,0 \mathrm{Ba}$ & $90,0 \mathrm{Ab}$ \\
\hline $\mathrm{S}_{2}$ & $0,0 \mathrm{Ba}$ & $60,0 \mathrm{Abc}$ & $86,4 \mathrm{Ac}$ & $85,5 \mathrm{Ab}$ & $0,0 \mathrm{Ba}$ & $89,2 \mathrm{Ab}$ \\
\hline $\mathrm{S}_{3}$ & 0,0 Ba & $67,8 \mathrm{Aa}$ & 96,9 Aab & 98,3 Aa & 0,0 Ba & 100,0 Aa \\
\hline $\mathrm{S}_{4}$ & $0,0 \mathrm{Ba}$ & $64,1 \mathrm{Aab}$ & $95,3 \mathrm{Bb}$ & 99,7 Aa & $0,0 \mathrm{Ba}$ & $100,0 \mathrm{Aa}$ \\
\hline $\mathrm{S}_{5}$ & 0,0 Ba & $56,7 \mathrm{Ac}$ & $100,0 \mathrm{Aa}$ & $99,4 \mathrm{Aa}$ & 0,0 Ba & 100,0 Aa \\
\hline CV(\%) & \multicolumn{2}{|c|}{11,2} & \multicolumn{2}{|c|}{2,0} & \multicolumn{2}{|c|}{3,3} \\
\hline DMS & \multicolumn{2}{|c|}{7,2} & \multicolumn{2}{|c|}{3,7} & \multicolumn{2}{|c|}{3,2} \\
\hline
\end{tabular}

Médias seguidas de mesmas letras, maiúsculas nas linhas e minúsculas nas colunas, não diferem entre si pelo teste Tukey a $5 \%$ de probabilidade; ${ }^{(1)}$ dac: dias após a colheita das culturas anuais (colheita dia 14 de abril de 2011); ${ }^{(2)} S_{1}$ - Soja em monocultura; $S_{2}$ - Soja e milheto (na safrinha, após a colheita da soja); $S_{3}$ - Milheto pré-soja e sobressemeadura de B. ruziziensis na soja no estádio $\mathrm{R}_{5.5} ; \mathrm{S}_{4}$ - Soja em sobressemeadura de milheto na soja no estádio $\mathrm{R}_{5.5} ; \mathrm{S}_{5}$ - Milho + braquiária em consórcio simultâneo; ${ }^{*}$ dessecação de manejo realizada em 23 de novembro de 2010

Tabela 5. Acúmulo de nitrogênio, fósforo e potássio na fitomassa das plantas cultivadas e invasoras nos sistemas de produção, no período de entressafra, avaliado em sete épocas, no cerrado piauiense

\begin{tabular}{|c|c|c|c|c|c|c|}
\hline \multirow[t]{4}{*}{ Sistema ${ }^{(2)}$} & \multirow{2}{*}{\multicolumn{2}{|c|}{ Dessecação* }} & \multicolumn{4}{|c|}{$\operatorname{dac}^{(1)}$} \\
\hline & & & \multicolumn{2}{|c|}{160} & \multicolumn{2}{|c|}{230} \\
\hline & SPC & SPD & SPC & SPD & SPC & SPD \\
\hline & \multicolumn{6}{|c|}{ Nitrogênio (kg ha-1) } \\
\hline $\mathrm{S}_{1}$ & $0,00 \mathrm{Ba}$ & $24,03 \mathrm{Ab}$ & $35,27 \mathrm{Ac}$ & $35,20 \mathrm{Ac}$ & $0,00 \mathrm{Ba}$ & $39,87 \mathrm{Ac}$ \\
\hline $\mathrm{S}_{2}$ & $0,00 \mathrm{Ba}$ & $23,20 \mathrm{Ab}$ & $37,90 \mathrm{Ac}$ & $38,85 \mathrm{Ac}$ & $0,00 \mathrm{Ba}$ & $40,63 \mathrm{Ac}$ \\
\hline $\mathrm{S}_{3}$ & $0,00 \mathrm{Ba}$ & $33,71 \mathrm{Aa}$ & 75,97 Ba & $81,47 \mathrm{Aa}$ & $0,00 \mathrm{Ba}$ & 152,22 Aa \\
\hline $\mathrm{S}_{4}$ & $0,00 \mathrm{Ba}$ & $34,75 \mathrm{Aa}$ & $60,44 \mathrm{Ab}$ & $62,23 \mathrm{Ab}$ & $0,00 \mathrm{Ba}$ & $116,15 \mathrm{Ab}$ \\
\hline $\mathrm{S}_{5}$ & $0,00 \mathrm{Ba}$ & $25,71 \mathrm{Ab}$ & $64,46 \mathrm{Ab}$ & $67,00 \mathrm{Ab}$ & $0,00 \mathrm{Ba}$ & $121,30 \mathrm{Ab}$ \\
\hline CV(\%) & \multicolumn{2}{|c|}{18,4} & \multicolumn{2}{|c|}{6,7} & \multicolumn{2}{|c|}{6,5} \\
\hline DMS & \multicolumn{2}{|c|}{5,23} & \multicolumn{2}{|c|}{7,73} & \multicolumn{2}{|c|}{6,23} \\
\hline & \multicolumn{6}{|c|}{ Fósforo (kg ha-1) } \\
\hline $\mathrm{S}_{1}$ & $0,00 \mathrm{Ba}$ & 6,68 Aa & $10,54 \mathrm{Bb}$ & $12,50 \mathrm{Ab}$ & $0,00 \mathrm{Ba}$ & $15,88 \mathrm{Ac}$ \\
\hline $\mathrm{S}_{2}$ & $0,00 \mathrm{Ba}$ & 6,39 Аa & $10,70 \mathrm{Bb}$ & $12,32 \mathrm{Ab}$ & $0,00 \mathrm{Ba}$ & $14,58 \mathrm{Ac}$ \\
\hline $\mathrm{S}_{3}$ & $0,00 \mathrm{Ba}$ & $6,44 \mathrm{Aa}$ & $11,80 \mathrm{Bb}$ & $15,27 \mathrm{Aa}$ & $0,00 \mathrm{Ba}$ & $44,91 \mathrm{Aa}$ \\
\hline $\mathrm{S}_{4}$ & $0,00 \mathrm{Ba}$ & 6,31 $\mathrm{Aa}$ & $15,84 \mathrm{Aa}$ & 14,09 Bab & $0,00 \mathrm{Ba}$ & $32,68 \mathrm{Ab}$ \\
\hline $\mathrm{S}_{5}$ & $0,00 \mathrm{Ba}$ & $5,39 \mathrm{Ab}$ & $11,97 \mathrm{Bb}$ & 15,91 $\mathrm{Aa}$ & $0,00 \mathrm{Ba}$ & $35,38 \mathrm{Ab}$ \\
\hline CV(\%) & \multicolumn{2}{|c|}{8,3} & \multicolumn{2}{|c|}{7,3} & \multicolumn{2}{|c|}{9,3} \\
\hline \multirow[t]{2}{*}{ DMS } & \multicolumn{2}{|c|}{0,53} & \multicolumn{2}{|c|}{1,97} & \multicolumn{2}{|c|}{2,72} \\
\hline & \multicolumn{6}{|c|}{ Potássio (kg ha $\left.{ }^{-1}\right)$} \\
\hline $\mathrm{S}_{1}$ & $0,00 \mathrm{Ba}$ & $5,29 \mathrm{Ac}$ & $23,68 \mathrm{Ac}$ & 13,79 Bd & $0,00 \mathrm{Ba}$ & $31,28 \mathrm{Ad}$ \\
\hline $\mathrm{S}_{2}$ & $0,00 \mathrm{Ba}$ & $6,87 \mathrm{Ac}$ & $23,40 \mathrm{Ac}$ & $22,23 \mathrm{Ac}$ & $0,00 \mathrm{Ba}$ & $32,91 \mathrm{Ad}$ \\
\hline $\mathrm{S}_{3}$ & $0,00 \mathrm{Ba}$ & $22,26 \mathrm{Ab}$ & $37,25 \mathrm{Ba}$ & 41,67 Aa & $0,00 \mathrm{Ba}$ & $136,07 \mathrm{Aa}$ \\
\hline $\mathrm{S}_{4}$ & $0,00 \mathrm{Ba}$ & $24,83 \mathrm{Aa}$ & $29,64 \mathrm{Bb}$ & $38,93 \mathrm{Aab}$ & $0,00 \mathrm{Ba}$ & $55,33 \mathrm{Ac}$ \\
\hline $\mathrm{S}_{5}$ & $0,00 \mathrm{Ba}$ & $20,31 \mathrm{Ab}$ & $34,73 \mathrm{Aa}$ & $36,50 \mathrm{Ab}$ & $0,00 \mathrm{Ba}$ & $79,47 \mathrm{Ab}$ \\
\hline CV(\%) & \multicolumn{2}{|c|}{18,0} & \multicolumn{2}{|c|}{7,9} & \multicolumn{2}{|c|}{4,8} \\
\hline DMS & \multicolumn{2}{|c|}{2,93} & \multicolumn{2}{|c|}{4,86} & \multicolumn{2}{|c|}{3,30} \\
\hline
\end{tabular}

Médias seguidas de mesmas letras, maiúsculas nas linhas e minúsculas nas colunas, não diferem entre si pelo teste Tukey ao nível de 5\%; ${ }^{(1)}$ DAC: dias após a colheita das culturas anuais (colheita dia 14 de abril de 2011); ${ }^{(2)} S_{1}$ - Soja em monocultura; $S_{2}$ - Soja e milheto (na safrinha, após a colheita da soja); S $_{3}$ - Milheto pré-soja e sobressemeadura de B. ruziziensis na soja no estádio $\mathrm{R}_{5.5} ; \mathrm{S}_{4}$ - Soja em sobressemeadura de milheto na soja no estádio $\mathrm{R}_{5.5} ; \mathrm{S}_{5}$ - Milho + braquiária em consórcio simultâneo; *dessecaçấo de manejo realizada em 23 de novembro de 2010 
Tabela 6. Acúmulo de cálcio e magnésio na fitomassa das plantas cultivadas e invasoras nos sistemas de produção, no período de entressafra, avaliado em sete épocas, no cerrado piauiense

\begin{tabular}{|c|c|c|c|c|c|c|}
\hline \multirow[t]{4}{*}{ Sistema ${ }^{(2)}$} & \multirow{2}{*}{\multicolumn{2}{|c|}{ Dessecação* }} & \multicolumn{4}{|c|}{$\operatorname{dac}^{(1)}$} \\
\hline & & & \multicolumn{2}{|c|}{160} & \multicolumn{2}{|c|}{230} \\
\hline & SPC & SPD & SPC & SPD & SPC & SPD \\
\hline & \multicolumn{6}{|c|}{ Cálcio (kg ha-1) } \\
\hline $\mathrm{S}_{1}$ & 0,00 Ba & $4,44 \mathrm{Ab}$ & $13,28 \mathrm{Abc}$ & $13,40 \mathrm{Aab}$ & 0,00 Ba & $15,57 \mathrm{Ac}$ \\
\hline $\mathrm{S}_{2}$ & $0,00 \mathrm{Ba}$ & 5,59 Aa & $12,18 \mathrm{Ac}$ & $12,37 \mathrm{Ab}$ & $0,00 \mathrm{Ba}$ & $16,02 \mathrm{Ac}$ \\
\hline $\mathrm{S}_{3}$ & $0,00 \mathrm{Ba}$ & $4,19 \mathrm{Abc}$ & $15,49 \mathrm{Aa}$ & $15,18 \mathrm{Aa}$ & 0,00 Ba & $27,77 \mathrm{Aa}$ \\
\hline $\mathrm{S}_{4}$ & $0,00 \mathrm{Ba}$ & 3,84 Acd & 14,50 Aab & $14,39 \mathrm{Aa}$ & $0,00 \mathrm{Ba}$ & $24,89 \mathrm{Ab}$ \\
\hline $\mathrm{S}_{5}$ & 0,00 Ba & 3,54 Ad & $15,40 \mathrm{Aa}$ & $15,05 \mathrm{Aa}$ & 0,00 Ba & $23,55 \mathrm{Ab}$ \\
\hline CV(\%) & \multicolumn{2}{|c|}{9,8} & \multicolumn{2}{|c|}{6,9} & \multicolumn{2}{|c|}{6,7} \\
\hline \multirow[t]{2}{*}{ DMS } & \multicolumn{2}{|c|}{0,43} & \multicolumn{2}{|c|}{1,99} & \multicolumn{2}{|c|}{1,48} \\
\hline & \multicolumn{6}{|c|}{ Magnésio $\left(\mathrm{kg} \mathrm{ha}^{-1}\right)$} \\
\hline $\mathrm{S}_{1}$ & 0,00 Ba & $5,30 \mathrm{Aa}$ & 10,04 Bb & $11,24 \mathrm{Ab}$ & 0,00 Ba & $14,93 \mathrm{Ac}$ \\
\hline $\mathrm{S}_{2}$ & 0,00 Ba & 4,77 Aab & $9,92 \mathrm{Bb}$ & $12,01 \mathrm{Ab}$ & 0,00 Ba & $14,90 \mathrm{Ac}$ \\
\hline $\mathrm{S}_{3}$ & 0,00 Ba & 4,19 Ab & 12,68 Ba & 15,11 Aa & 0,00 Ba & 31,93 Аa \\
\hline $\mathrm{S}_{4}$ & $0,00 \mathrm{Ba}$ & $5,40 \mathrm{Aa}$ & $12,18 \mathrm{Ba}$ & $14,58 \mathrm{Aa}$ & $0,00 \mathrm{Ba}$ & $23,54 \mathrm{Ab}$ \\
\hline $\mathrm{S}_{5}$ & $0,00 \mathrm{Ba}$ & $5,00 \mathrm{Aa}$ & $11,85 \mathrm{Ba}$ & 13,79 Aa & $0,00 \mathrm{Ba}$ & $21,59 \mathrm{Ab}$ \\
\hline CV(\%) & \multicolumn{2}{|c|}{14,5} & \multicolumn{2}{|c|}{6,3} & \multicolumn{2}{|c|}{9,7} \\
\hline DMS & \multicolumn{2}{|c|}{0,73} & \multicolumn{2}{|c|}{1,60} & \multicolumn{2}{|c|}{2,12} \\
\hline
\end{tabular}

Médias seguidas de mesmas letras, maiúsculas nas linhas e minúsculas nas colunas, não diferem entre si pelo teste Tukey ao nível de $5 \%$; ${ }^{(1)}$ dac: dias após a colheita das culturas anuais (colheita dia 14 de abril de 2011); ${ }^{(2)} S_{1}$ - Soja em monocultura; $S_{2}$ - Soja e milheto (na safrinha, após a colheita da soja); $S_{3}$ - Milheto pré-soja e sobressemeadura de B. ruziziensis na soja no estádio $\mathrm{R}_{5,5} ; \mathrm{S}_{4}$ - Soja em sobressemeadura de milheto na soja no estádio $\mathrm{R}_{5,5} ; \mathrm{S}_{5}$ - Milho + braquiária em consórcio simultâneo; *dessecaçāo de manejo realizada em 23 de novembro de 2010

com satisfatória tolerância às condiçôes edafoclimáticas da região. Estudos de PACHeCo et al. (2008) demonstraram potencialidades dessas espécies em sobressemeadura nas condiçôes do cerrado goiano. A diferença entre os dois estudos está no fato de que no presente experimento a sobressemeadura das espécies na soja foi realizada de forma mais precoce, no estádio $\mathrm{R}_{5.5}(80 \%$ de grãos cheios), enquanto no estudo de Pacheco et al. (2008) ela ocorreu no início da senescência da soja $\left(\mathrm{R}_{5,6}, 100 \%\right.$ grãos cheios). Essas alteraçôes são justificadas pela ocorrência de menor disponibilidade hídrica após a colheita das culturas anuais no cerrado piauiense e pela necessidade de proporcionar condições mais adequadas ao desenvolvimento inicial das plantas de cobertura. LARA-Cabezas (2004) destacaram a sobressemeadura com uso de $P$. glaucum e $U$. ruziziensis como alternativa viável para a formação e a manutenção de palhada em SPD no cerrado goiano.

No consórcio milho $+U$. ruziziensis e após a colheita da cultura anual, a $U$. ruziziensis apresentava-se com o sistema radicular e parte aérea já desenvolvidos, o que proporcionou significativo acúmulo de FS e TCS durante o período de entressafra. KLUTHCOUSKI e AidAR (2003) observaram que o consórcio de plantas forrageiras e culturas anuais proporcionou baixa produçáo da forragem na época de colheita da cultura anual (safra verão), mas rápido desenvolvimento da forrageira após o início da senescência do milho. Görgen et al. (2010) observaram que as espécies de Urochloa consorciadas com milho possibilitaram produção de fitomassa em quantidade suficiente para a condução do SPD em condiçôes tropicais.
O uso de $P$. glaucum semeado após a colheita da soja $\left(S_{2}\right)$ foi inviável para as condiçóes do cerrado piauiense, uma vez que o estresse hídrico e a alta temperatura provocaram significativa redução na germinaçáo e desenvolvimento das plantas de P. glaucum. Esses resultados indicam a importância da umidade no solo para os estádios iniciais de crescimento de P. glaucum.

É importante destacar que os restos culturais da soja e do milho possibilitaram produção de fitomassa extra para o sistema de $5.500 \mathrm{~kg} \mathrm{ha}^{-1}$ para $S_{1}, S_{2}, S_{3}$ e $S_{4}$ e de $6.500 \mathrm{~kg} \mathrm{ha}^{-1}$ para $S_{5}$. Ao considerar esses valores e a produção de fitomassa acumulada pelas plantas de cobertura aos 230 dac (Tabela 4), os valores ultrapassam $16 \mathrm{mil} \mathrm{kg} \mathrm{ha}^{-1} \mathrm{ano}^{-1}$ de FS nos tratamentos $S_{3}, S_{4}$ e $S_{5}$, superiores ao mínimo (13 mil kg ha ${ }^{-1}$ ano $\left.^{-1}\right)$ recomendado para as regiôes do cerrado do Brasil Central. Alvarenga et al. (2001) observaram que a maximização dos benefícios da SPD na regiâo dos cerrados tem como maiores desafios a produçáo de pelo menos $12 \mathrm{mil} \mathrm{kg} \mathrm{ha}^{-1}$ de fitomassa por ano. Ao considerar que a temperatura média no cerrado piauiense é mais elevada, espera-se que a quantidade mínima de FS para o adequado desenvolvimento do SPD seja maior, o que reforça a potencialidade dos sistemas $S_{3}, S_{4}$ e $S_{5}$.

Os acúmulos de FS nos sistemas com uso de sobressemeadura de $U$. ruziziensis $\left(\mathrm{S}_{3}\right)$ e $P$. glaucum $\left(\mathrm{S}_{4}\right)$ na soja e no consórcio simultâneo de milho $+U$. ruziziensis $\left(\mathrm{S}_{5}\right)$ foram exponenciais crescentes (Figura 2), com as maiores taxas de acúmulo no final do período de entressafra, em razão do reinício das chuvas no mês de outubro (Figura 1) 


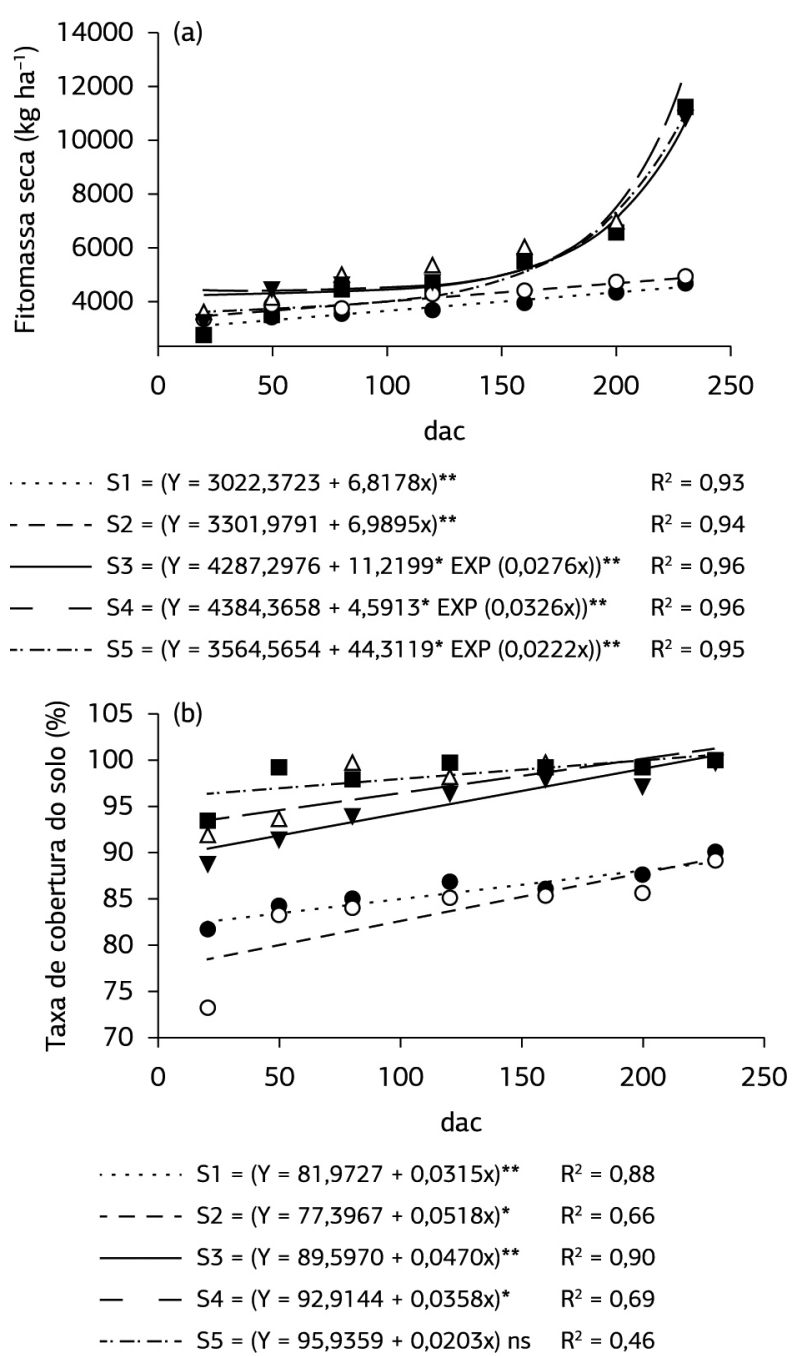

Figura 2. Fitomassa seca (a) e taxa de cobertura do solo (b) das plantas de cobertura em diferentes sistemas de manejo avaliadas no período entressafra, safra 2011/2012, no cerrado piauiense.

e rebrota ou germinação de novas plantas. Os sistemas com pousio $\left(\mathrm{S}_{1}\right)$ e $P$. glaucum semeado após a colheita da soja $\left(\mathrm{S}_{2}\right)$ apresentaram produção linear crescente de FS e TCS, com baixos acréscimos durante a entressafra (Figura 2), mesmo após o reinício das chuvas (Figura 1), sendo opçóes menos viáveis para o SPD.

Os resultados demonstram que as parcelas submetidas ao SPD possibilitam maior produção de FS e TCS no período entre o final da entressafra e início da safra seguinte (160 e 230 dias após a colheita das culturas anuais, nos meses de outubro e novembro), em razão do não revolvimento do solo e da possibilidade de acréscimos significativos na produção de FS que ocorre após o reinício das chuvas nesse período. Esses resultados estão de acordo com PACHECo et al. (2011), que obtiveram aumento de FS e TCS de plantas de cobertura no SPD após o reinício das chuvas no período de entressafra. Em SPC, o preparo do solo realizado com antecedência de pelo menos 45 dias antes da semeadura das culturas anuais desfavorece o acúmulo de FS com o reinício das chuvas e aumenta a suscetibilidade do solo à erosão hídrica. Segundo Carvalho et al. (2004), o uso do solo sob SPC pode causar, além da compactação, a redução da estabilidade dos agregados, aumentando a propensão à perda de solo.

No acúmulo de nutrientes, observou-se que os sistemas com uso de sobressemeadura de $U$. ruziziensis $\left(S_{3}\right)$ e P. glaucum $\left(\mathrm{S}_{4}\right)$ na soja e que o consórcio simultâneo de milho + U. ruziziensis $\left(\mathrm{S}_{5}\right)$ apresentaram as maiores potencialidades (Tabelas 5 e 6). Esses resultados podem ser explicados pelo significativo crescimento dessas espécies durante a entressafra, com destaque para a rebrota/germinaçáo de novas plantas após o reinício das chuvas (entre 160 e 230 dias após colheita), além da elevada capacidade de absorção de nutrientes do solo, mesmo sob restrita quantidade de água nele disponível.

Verificou-se que o acúmulo de nutrientes nos sistemas $\mathrm{S}_{3}, \mathrm{~S}_{4}$ e $\mathrm{S}_{5}$ foi exponencial crescente, com destaque para a alta taxa de acúmulo que ocorreu ao final do período de entressafra (Figura 3). Os nutrientes com maior acúmulo foram N (152 kg ha $\left.{ }^{-1}\right), \mathrm{K}\left(136 \mathrm{~kg} \mathrm{ha}^{-1}\right), \mathrm{P}\left(44 \mathrm{~kg} \mathrm{ha}^{-1}\right), \mathrm{Mg}$ $\left(32 \mathrm{~kg} \mathrm{ha}^{-1}\right)$ e Ca $\left(27 \mathrm{~kg} \mathrm{ha}^{-1}\right)$. Esses resultados demonstram que a ciclagem de nutrientes em SPD está relacionada com a frequência e o volume pluviométrico que ocorre entre o final da entressafra e a data da dessecaçáo de manejo para semeadura das culturas anuais. Trabalhos realizados por BrAz et al. (2004) indicam grande acúmulo de $\mathrm{N}\left(348 \mathrm{~kg} \mathrm{ha}^{-1}\right)$ e K $\left(314 \mathrm{~kg} \mathrm{ha}^{-1}\right)$ em $P$. glaucum semeado no verão em regiáo do cerrado com elevado índice pluviométrico e elevadas temperaturas. Boer et al. (2007) obtiveram significativo acúmulo de fitomassa e nutrientes pelo $P$. glaucum, com destaque para o acúmulo de mais de $400 \mathrm{~kg} \mathrm{ha}^{-1}$ de $\mathrm{K}$, favorecido por elevadas precipitaçóes e temperaturas. $\mathrm{O}$ menor acúmulo de nutrientes neste trabalho pode estar relacionado à menor fertilidade do solo no Piauí e à restriçáo hídrica que desfavorece a absorção iônica, uma vez que as áreas cultivadas dessa região encontram-se com poucos anos de cultivo e em processo de correção da fertilidade do solo.

A produtividade de grãos de soja e milho foi afetada pelos sistemas de manejo do solo e de cultivo com plantas de cobertura (Tabela 7). Observou-se que a cultura da soja apresentou satisfatória adaptabilidade ao SPD recém-implantado, com destaque para os tratamentos com uso de pousio e $P$. glaucum em sobressemeadura na soja na safra anterior. $\mathrm{O}$ milho apresentou redução na produtividade no SPD, que é justificado pela recém-implantação desse sistema e pela imobilização de $\mathrm{N}$ pela microbiota para formação de matéria orgânica do solo. Para a obtenção de elevada produtividade, o milho necessita ter suas exigências nutricionais plenamente satisfeitas, de forma a atender-se a grande demanda de extraçáo de nutrientes do solo, em especial de nitrogênio. Esse nutriente, além de ser extraído em maior quantidade, tem recomendação de adubação e manejo mais complexos (Cantarella e Duarte, 2004; 

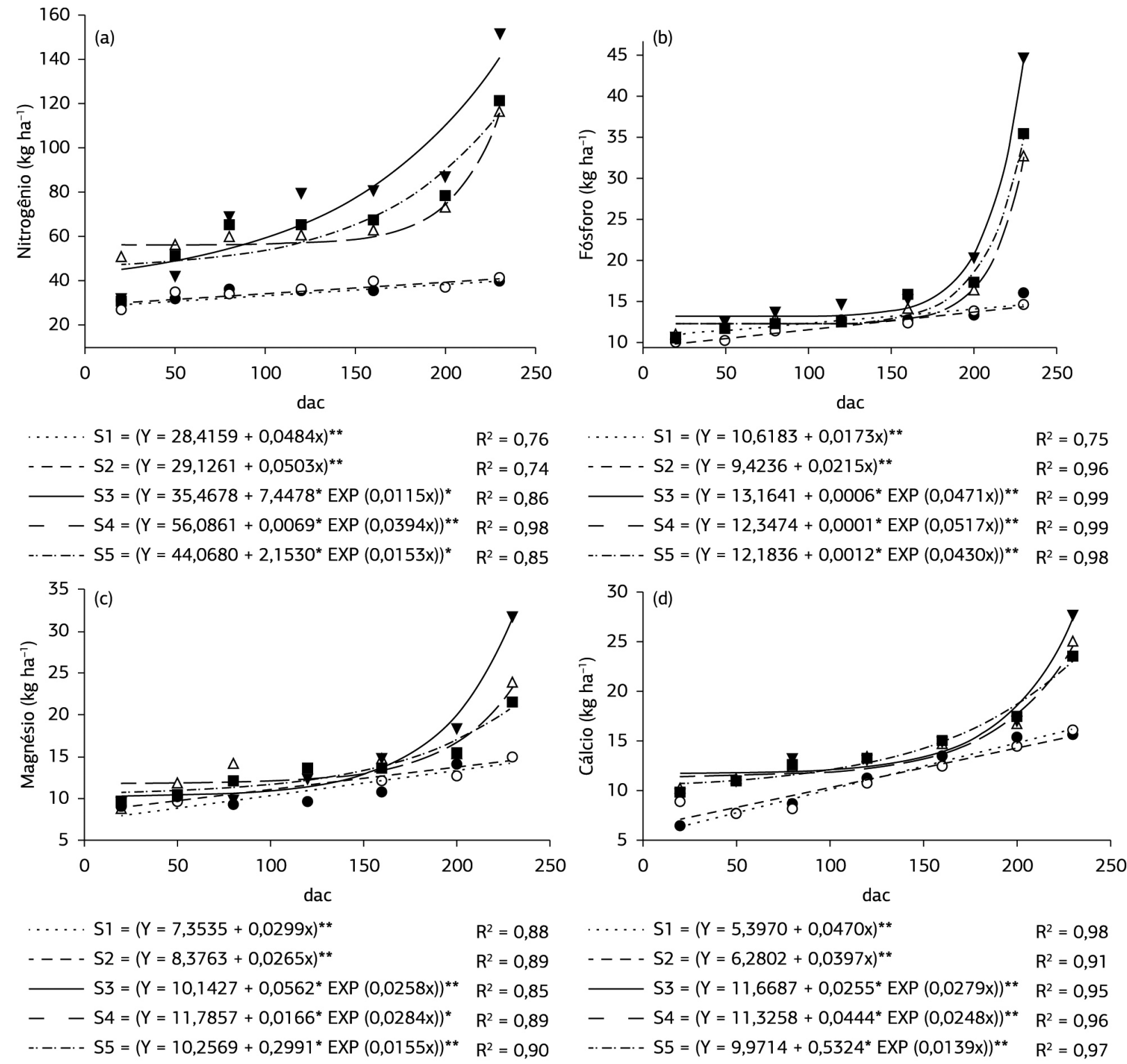

$$
\begin{aligned}
& \text { … S1 }=(Y=5,3970+0,0470 x)^{* *} \\
& R^{2}=0,98 \\
& \text { - - - } \mathrm{S} 2=(\mathrm{Y}=6,2802+0,0397 \mathrm{x})^{* *} \\
& R^{2}=0,91 \\
& \mathrm{S3}=\left(\mathrm{Y}=11,6687+0,0255^{*} \operatorname{EXP}(0,0279 \mathrm{x})\right)^{* *} \\
& R^{2}=0,95 \\
& -\quad-\mathrm{S} 4=\left(\mathrm{Y}=11,3258+0,0444^{*} \operatorname{EXP}(0,0248 \mathrm{x})\right)^{* *} \\
& R^{2}=0,96 \\
& \text {-. -.-.- S5 }=(Y=9,9714+0,5324 * \operatorname{EXP}(0,0139 x))^{* *} \\
& R^{2}=0,97
\end{aligned}
$$

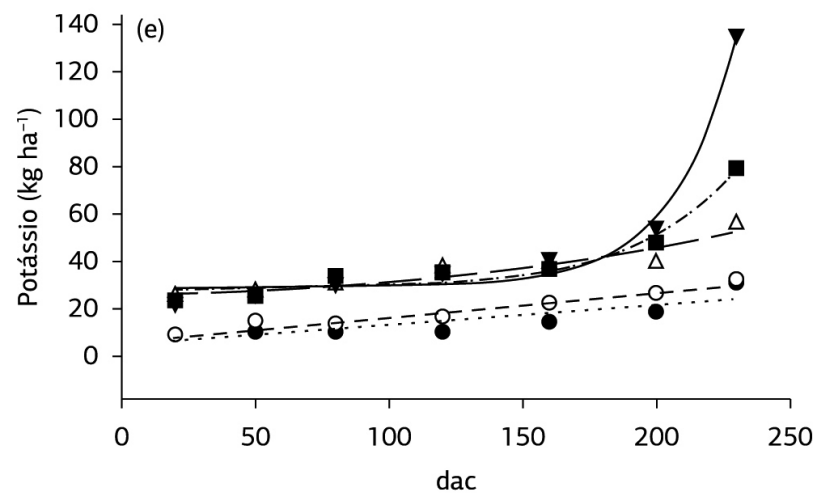

$$
\begin{aligned}
\ldots . . S 1=(Y=4,3970+0,0878 x)^{* *} & R^{2}=0,74 \\
---S 2=(Y=5,2802+0,1042 x)^{* *} & R^{2}=0,92 \\
-S 3=\left(Y=29,1817+0,0057^{*} \operatorname{EXP}(0,0428 x)\right)^{* *} & R^{2}=0,98 \\
--S 4=\left(Y=21,4669+4,1459^{*} \operatorname{EXP}(0,0087 x)\right)^{* *} & R^{2}=0,89 \\
---\cdot S 5=\left(Y=28,1866+0,1174^{*} \operatorname{EXP}(0,0264 x)\right)^{* *} & R^{2}=0,96
\end{aligned}
$$

Figura 3. Acúmulo de nitrogênio (a), fósforo (b), potássio (c), cálcio (d) e magnésio (e) na fitomassa das plantas de cobertura nos diferentes sistemas de produção no período entressafra, safra 2011/2012, no cerrado piauiense. 
Tabela 7. Produtividade de soja e milho no período de safra 2010/2011, no cerrado piauiense

\begin{tabular}{|c|c|c|}
\hline \multirow[t]{3}{*}{ Sistema } & \multicolumn{2}{|c|}{ Produtividade $\left(\mathrm{kg} \mathrm{ha}^{-1}\right)$} \\
\hline & \multicolumn{2}{|c|}{ Soja } \\
\hline & SPC & SPD \\
\hline $\mathrm{S}_{1}$ & $3.229,59 \mathrm{Ba}$ & $3.707,35 \mathrm{Aa}$ \\
\hline $\mathrm{S}_{2}$ & 3.405,27 Aa & $3.638,68 \mathrm{Aa}$ \\
\hline $\mathrm{S}_{3}$ & 3.413,32 Aa & $3.583,43 \mathrm{Aa}$ \\
\hline \multirow[t]{2}{*}{$\mathrm{S}_{4}$} & $3.040,60 \mathrm{Ba}$ & $3.608,82 \mathrm{Aa}$ \\
\hline & \multicolumn{2}{|c|}{ Milho } \\
\hline $\mathrm{S}_{5}$ & $6.902,74 \mathrm{~A}$ & $6.215,48$ B \\
\hline CV(\%) & \multicolumn{2}{|c|}{7,0} \\
\hline DMS & \multicolumn{2}{|c|}{588,31} \\
\hline
\end{tabular}

Médias seguidas de mesmas letras, maiúsculas nas linhas e minúsculas nas colunas, não diferem entre si pelo teste tukey considerando o nível de 5\% de significância

Silva et al., 2005). Dessa forma, é importante a realização de trabalhos que possam estudar o manejo da adubação nitrogenada no milho, a fim de se conhecerem as dosagens e épocas de aplicação em SPD no cerrado piauiense.

\section{CONCLUSÕES}

A sobressemeadura de Urochloa ruziziensis $\left(S_{3}\right)$ e Pennisetum glaucum $\left(\mathrm{S}_{4}\right)$ na soja e o consórcio de milho + Urochloa ruziziensis $\left(\mathrm{S}_{5}\right)$ destacam-se na produçáo de fitomassa seca, taxa de cobertura do solo e acúmulo de nutrientes no cerrado piauiense, com alto acúmulo de nitrogênio e potássio. A cultura da soja apresenta-se como opção viável para cultivo em sistema plantio direto nos primeiros anos de adoção.

\section{AGRADECIMENTOS}

À Celeiro Sementes e ao Conselho Nacional de Desenvolvimento Científico e Tecnológico pelo apoio e auxílio financeiro ao projeto e concessão de bolsa de mestrado para o segundo autor (CNPq, n. 477208/2010-0).

\section{REFERÊNCIAS}

ALVARENGA, R.C.; LARA-CABEZAS, W.A.; CRUZ, J.C.; SANTANA, D.P. Plantas de cobertura de solo para sistema plantio direto. Informe Agropecuário, v.22, p.25-36, 2001.

BRAZ, A.J.B.P.; SILVEIRA, P.M.; KLIEMANN, H.J.; ZIMMERMANN, F.J.P. Acumulaçáo de nutrientes em folhas de milheto e dos capins braquiária e mombaça. Pesquisa Agropecuária Tropical, v.34, p.83-87, 2004.

BOER, C.A.; ASSIS, R.L.; SILVA, G.P.; BRAZ, A.J.B.P.; BARROSO, A.L.L.; CARGNELUTTI FILHO, A.; PIRES, F.R. Ciclagem de nutrientes por plantas de cobertura na entressafra em um solo de Cerrado. Pesquisa Agropecuária Brasileira, v.42, p.1269-1276, 2007. http://dx.doi.org/10.1590/S0100-204X2007000900008

BORGHI, E.; CRUSCIOL, C.A.C.; COSTA, C. Desenvolvimento da cultura do milho em consorciação com Brachiaria brizantha em sistema plantio direto. Energia na Agricultura, v.21, p.19-33, 2006.

CANTARELLA, H., DUARTE, A.P. Manejo da fertilidade do solo para a cultura do milho. In: GALVÁO, J. C. C.; MIRANDA, G. V. (Ed.). Tecnologia de produção de milho. Viçosa: Universidade Federal de Viçosa, 2004. p.139-182.

CARNEIRO, M.A.C.; CORDEIRO, M.A.S.; ASSIS, P.C.R.; MORAES, E.S.; PEREIRA, H.S.; PAULINO, H.B.; SOUSA, E.D. Produção de fitomassa de diferentes espécies de cobertura e suas alteraçôes na atividade microbiana de solo de Cerrado. Bragantia, v.67, p.455462, 2008. http://dx.doi.org/10.1590/S0006-87052008000200021

CARVALHO, A.M.; SOUZA, L.L.P.; GUIMARÃES JÚNIOR, R.; ALVES, P.C.A.C.; VIVALDI, L.J. Cover plants with potential use for crop livestock integrated systems in the Cerrado region. Pesquisa Agropecuária Brasileira, v.46, p.1200-1205, 2011. http://dx.doi. org/10.1590/S0100-204X2011001000012

CARVALHO, M.A.C.; ATHAYDE, M.L.F.; SORATTO, R.P.; ALVES, M.C.; ARF, O. Soja em sucessão a adubos verdes no sistema de plantio direto e convencional em solo de Cerrado. Pesquisa Agropecuária Brasileira, v.39, p.1141-1148, 2004. http://dx.doi.org/10.1590/ S0100-204X2004001100013

COMPANHIA NACIONAL DE ABASTECIMENTO - CONAB. $5^{\circ}$ Levantamento da Produção de Grãos - Safra 2011/12. Brasília: CONAB, 2012. Disponível em: <http://www.conab.gov.br>.

CRUSCIOL, C.A.C.; COTTICA, R.L.; LIMA, E.V.; ANDREOTTI, M.; MORO, E.; MARCON, E. Persistência de palhada e liberação de nutrientes do nabo forrageiro no plantio direto. Pesquisa Agropecuária Brasileira, v.40, p.161-168, 2005. http://dx.doi.org/10.1590/S0100204X2005000200009

CRUSCIOL, C.A.C.; SORATTO, R.P. Nutrição e produtividade do amendoim em sucessáo ao cultivo de plantas de cobertura no sistema plantio direto. Pesquisa Agropecuária Brasileira, v.42, p.15531560, 2007. http://dx.doi.org/10.1590/S0100-204X2007001100006

CRUZ, I.; CIOCIOLA JÚNIOR, A.L. Manejo da cultura do milho em sistema de plantio direto. Informe Agropecuário, v.27, p.42-53, 2006.

GÖRGEN, C.A.; CIVARDI, E.A.; RAGAGNI, V.A.; SILVEIRA NETO, A.N.; CARNEIRO, L.C.; LOBO JUNIOR, M. Redução do inóculo inicial de Sclerotinia sclerotiorum em soja cultivada após uso do sistema Santa Fé. Pesquisa Agropecuária Brasileira, v.45, p.11021108, 2010. http://dx.doi.org/10.1590/S0100-204X2010001000008

KLUTHCOUSKI, J.; AIDAR, H. Implantação, condução e resultados obtidos com sistema Santa Fé. In: KLUTHCOUSKI, J.; STONE, L.F.; AIDAR, H. (Ed.). Integração lavoura-pecuária. Santo Antônio de Goiás: Embrapa arroz e feijão, 2003. p.407-441.

LARA-CABEZAS, W.R.L.; ALVES, B.J.R.; URQUIAGA, S.; SANTANA, D.G. Influência da cultura antecessora e da adubação nitrogenada na produtividade de milho em sistema plantio direto e solo preparado. Ciência Rural, v.34, p.1005-1013, 2004. http:// dx.doi.org/10.1590/S0103-84782004000400006 
LARA-CABEZAS, W.A.R. Sobressemeadura com sementes de milheto revestidas no Triângulo Mineiro-MG: estudo preliminar. Revista Plantio Direto, v.79, p.13-21, 2004.

MORETI, D.; ALVES, M.C.; VALÉRIO FILHO, W.V.; CARVALHO, M.P. Atributos químicos de um Latossolo Vermelho sob diferentes sistemas de preparo, adubações e plantas de cobertura. Revista Brasileira de Ciência do Solo, v.31, p.167-175, 2007. http://dx.doi. org/10.1590/S0100-06832007000100017

NOGUEIRA, A.R.A.; CARMO, C.A.F.S.; MACHADO, P.L.O.A. Tecido vegetal. In: NOGUEIRA, A.R.A.; SOUZA, G.B.; MACHADO, P.L.O.A.; CARMO, C.A.F.S.; FERREIRA, J.R. (Ed.). Manual de laboratórios: solo, água, nutrição vegetal, nutrição animal e alimentos. São Carlos: Embrapa Pecuária Sudoeste, 2005. p.145-199.

PACHECO, L.P.; PIRES, F.R.; MONTEIRO, F.P.; PROCOPIO, S.O.; ASSIS, R.L.; CARMO, M.L.; PETTER, F.A. Desempenho de plantas de cobertura em sobressemeadura na cultura da soja. Pesquisa Agropecuária Brasileira, v.43, p.815-823, 2008. http:// dx.doi.org/10.1590/S0100-204X2008000700005

PACHECO, L.P; LEANDRO, W.M.; MACHADO, P.L.O.A; ASSIS, R.L.; COBUCCI, T.; MADARI, B.E.; PETTER, F.A. Produção de fitomassa e acúmulo e liberaçáo de nutrientes por plantas de cobertura na safrinha. Pesquisa Agropecuária Brasileira, v.46, p.17-25, 2011. http://dx.doi.org/10.1590/S0100-204X2011000100003
PIRES, F.R.; ASSIS, R.L.; PROCÓPIO, S.O.; SILVA, G.P.; MORAES, L.L.; RUDOVALHO, M.C.; BÔER, C.A. Manejo de plantas de cobertura antecessoras à cultura da soja em plantio direto. Revista Ceres, v.55, p.94-101, 2008.

PRAGANA, R.B.; RIBEIRO, M.R.; NÓBREGA, J.C.A.; RIBEIRO FILHO, M.R.; COSTA, J.A. Qualidade física de Latossolos Amarelos sob plantio direto na regiáo do Cerrado piauiense. Revista Brasileira de Ciência do Solo, v.36, p.1591-1600, 2012. http://dx.doi.org/10.1590/ S0100-06832012000500023

SILVA, A.A.; FREITAS, F.M.; FERREIRA, L.R.; JAKELAITIS, A.; SILVA, A.F. Aplicações seqüenciais e épocas de aplicação de herbicidas em misturas com chlorpirifos no milho e em plantas daninhas. Planta Daninha, v.23, p.527-534, 2005. http://dx.doi.org/10.1590/S010083582005000300017

SILVA, T.O.; FURTINI NETO, A.E.; CARNEIRO, L.F.; PALUDO, V. Plantas de cobertura submetidas a diferentes fontes de fósforo em solos distintos. Ciências Agrárias, v.32, p.1315-1326, 2011. http:// dx.doi.org/10.5433/1679-0359.2011v32n4p1315

SODRÉ FILHO, J.; CARDOSO, A.N.; CARMONA, R.; CARVALHO, A.M. Fitomassa e cobertura do solo de culturas de sucessão ao milho na região do cerrado. Pesquisa Agropecuária Brasileira, v.39, p.327334, 2004. http://dx.doi.org/10.1590/S0100-204X2004000400005 